This article has been scanned by iThenticat No plagiarism detected

Volume 3, Issue 5, October 2021

p. $13-28$

\title{
GEOGRAPHICAL ANALYSIS OF THE EDUCATIONAL WORK FORCE FOR PRIMARY EDUCATION IN IRAQ
}

http://dx.doi.org/10.47832/2757-5403.5-3.2

Aseel Ibrahim Talib Hayawi AL-QAISI 1

\begin{abstract}
:
Proper planning requires in-depth population studies and a broad knowledge of all aspects related to human resources in terms of their growth, distribution and characteristics. The size of the workforce in any human society is the true indicator of its economic and production potential and the power to drive it. The research dealt with the geographical distribution of the workforce in the field of primary education in Iraq according to For the latest statistics provided by the Iraqi Ministry of Education, in light of the Population Geography approach, which is concerned with analyzing and interpreting spatial differences, distribution patterns, and the factors that explain it.

The study aims to analyze the geographical distribution of the workforce in the field of primary education at the governorate level, and the descriptive analytical approach has been relied on and the statistical method is used to show the variables of the characteristics of the workforce.

It was found through the research that the governorate of Baghdad led the number and percentages of the educational workforce in the primary stage, which amounted to $(24.8 \%)$ for the academic year $2018 / 2019$, followed by the governorates of Dhi Qar and Basra with close proportions amounting to $(7.8 \%)$ and $(7.6 \%)$ respectively, then Babil Governorate. Diyala has a similar rate of $(6.4 \%)$, and the proportions of the educational workforce varied in terms of gender, as it increased for females by $(67.1 \%)$ compared to $(32.9 \%)$ for males. As for the distribution of the educational workforce according to the environment, the urban environment came at a high rate of (67\%) and a low rate for the rural environment amounting to (33\%), which reflects the inequality of distribution according to the environment as a result of the concentration of educational services in urban areas compared to
\end{abstract}

\footnotetext{
${ }^{1}$ Researcher, Ministry of Education / Baghdad Education Directorate / Rusafa First, Iraq, Asselbrihem75@gmail.com, https://orcid.org/0000-0001-9376-1009
}

Copyright $(\odot$ Published by IJHER Journal, www.ijherjournal.com Rimar Academy, Fatih, Istanbul, 34093 Turkey

All rights reserved 
their limitations and decline in rural areas, and it became clear that the education sector suffers from a severe shortage of educational staff for some specializations at the level of education Primary.

The research recommended the necessity of equitable distribution of the workforce to match the number with the population of the governorates, as well as expanding the establishment of a greater number of primary schools outside the governorates center and in rural areas.

Key words: Geographical Analysis, Primary Education, Educational Workforce.

\section{تحليل جغرافي للقوى العاملة التعليمية لمرحلة التعليم الابتدائي في العراق \\ أسيل ابراهيم طالب حياوي القيسي 2}

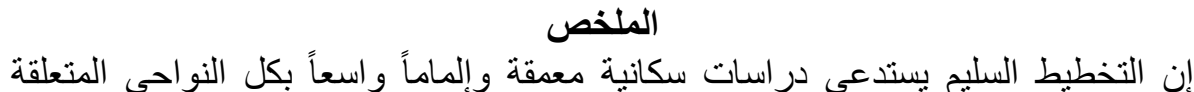

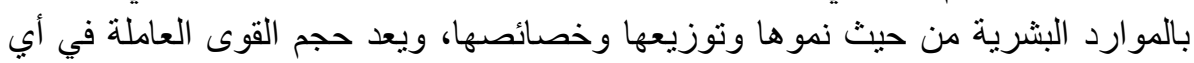

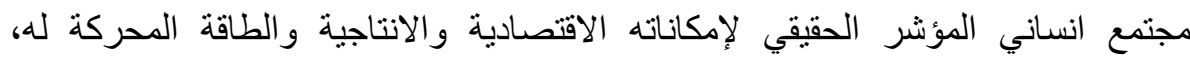

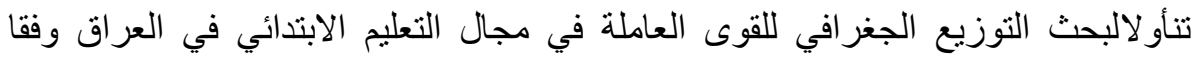

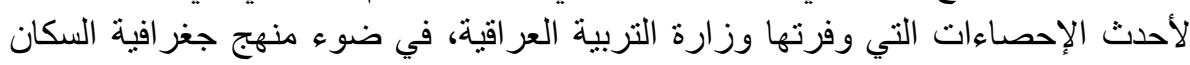

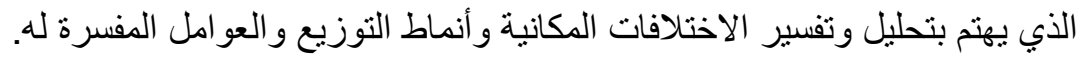

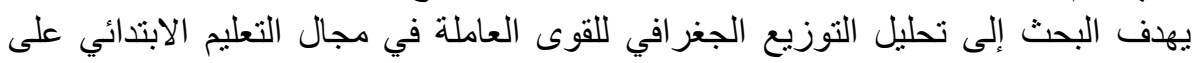

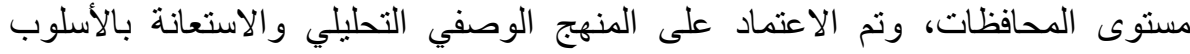

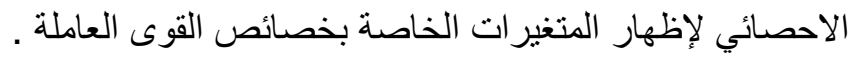

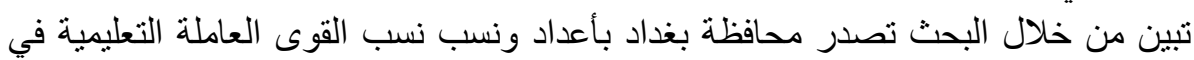
الدرحلة الابندائية و التي بلغت (24.8 \% \%) للعام الدراسي 2018/

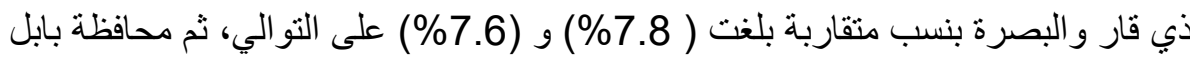

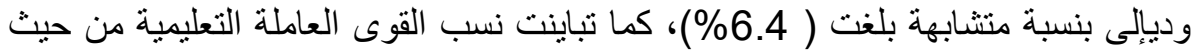

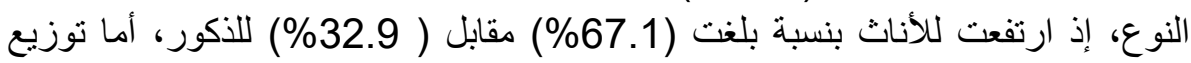

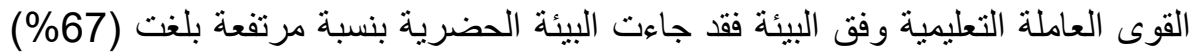

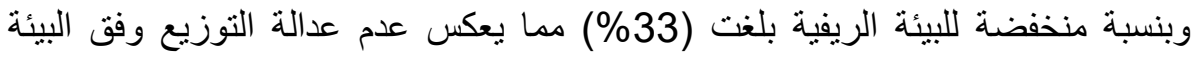

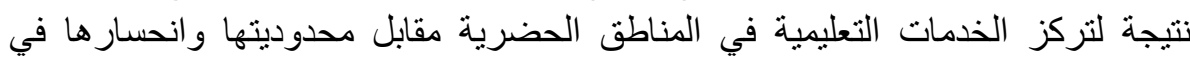

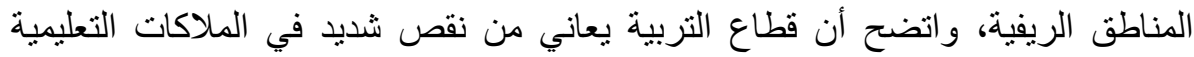
الخاصة بعضض التخصصات على مستوى النعليم الابتدائي.

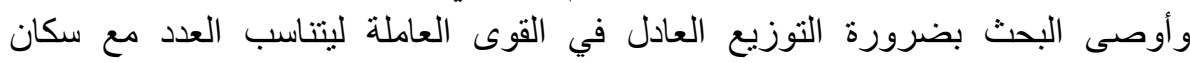

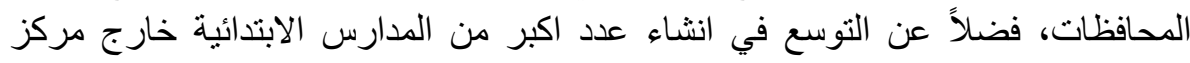
المحافظات وفي المناطق الريفية. الكلمات المفتاحية: تحليل جغرافي، القوى العاملة التعليمية، التعليم الابتدائي. 
تعتمد طبيعة عمل كافة المؤسسات في بيئة العمل على وجود العاملين في قطاعاتها الوظيفية المختلفة، مما يسهم في الحفاظ

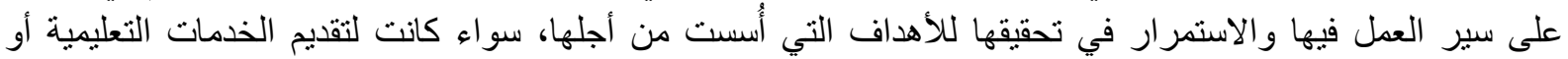

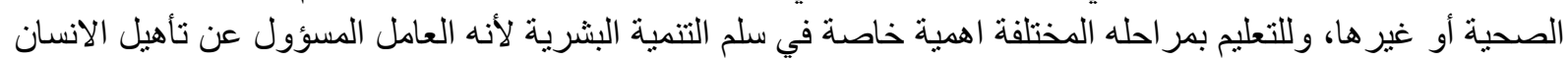

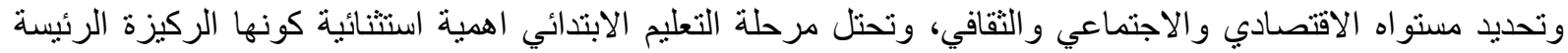

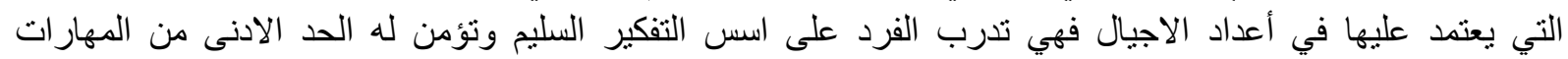

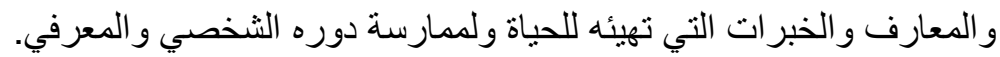

مشكلة البحث وتساؤلاتها

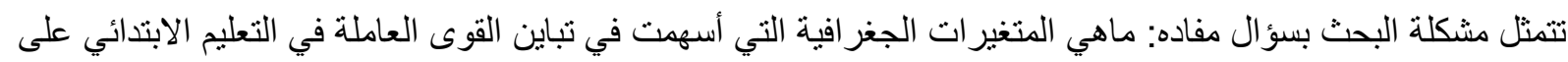

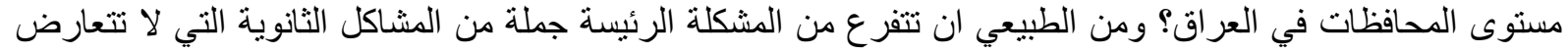

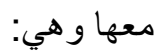
1- ما حجم القوى العاملة في مجال التعليم الابتدائي في العراق؟ وماسبب هذا التباين؟

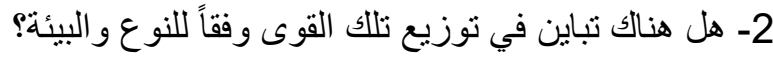
3-هل هناك تناسب بين توزيع القوى العاملة التعليمية و الحجم السكاني للمحافظات؟

$$
\text { فرضية البحث: }
$$

يفترض الباحث ان هنالك عوامل ومتغيرات جغرافية اسهمت في تباين توزيع القوى العاملة التعليمية في مرحلة التعليم

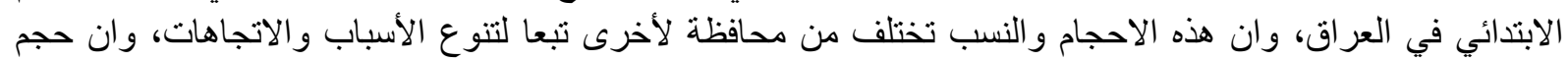

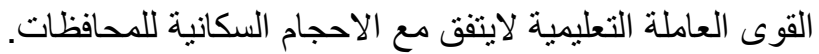

$$
\text { هدف البحث }
$$

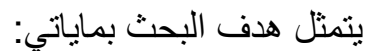
1- معرفة أهم العو امل والاسباب المؤثرة في التباين المكاني للقوى العاملة التعليمية. 2- مساعدة المؤسسة التعليمية على أعداد خُططها ومعرفة الهُ أهدافها. 3- مز امنة الهيكل الوظيفيّ مع الهيكل التنظيمي.

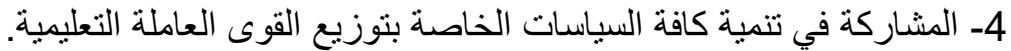
5- ـ ـ تحقيق أفضل استفادة من الموارد البشريّة المتاحة. 6- التقليل انتشار البطالة المقنّعة في المجتمع و المُساهمة في تقليل نسبة العجنة العزئة من القوى العاملة.

\section{منهجية البحث ومصادره:}

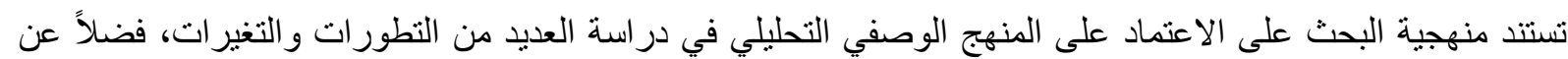
استعمال الاساليب الاحصائية المختلفة لاثبات فرضية البحث، والئهي الإنمدت الباحثة على البيانات الرسمية من وزارة التخطيط

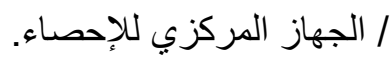

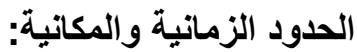

أن أطار الدراسة الزمني حدد للعام الدراسي 2019/2018 وهو الاحدث بين الدراسات من حيث بياناتها واحصاءاتها، اما الحدود المكانية فتحدد بمحافظات العراق التي بلغت (15 وحدة إداريه ) باستثناء إقليم كردستان الذي لم تتح للباحث 


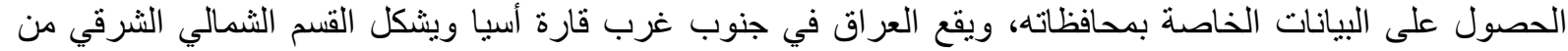

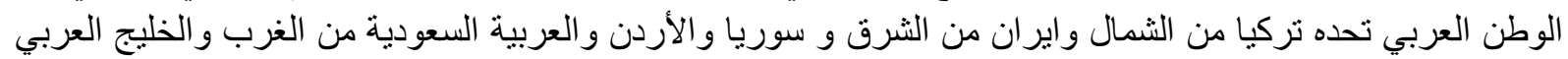

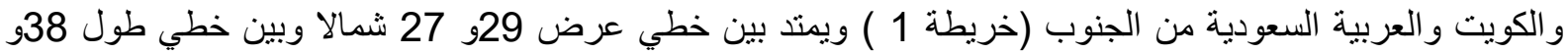

48 شرقا وتبلغ مساحته (435.025) كم2(1) خريطة (1) العراق وتقسيماته الإدارية

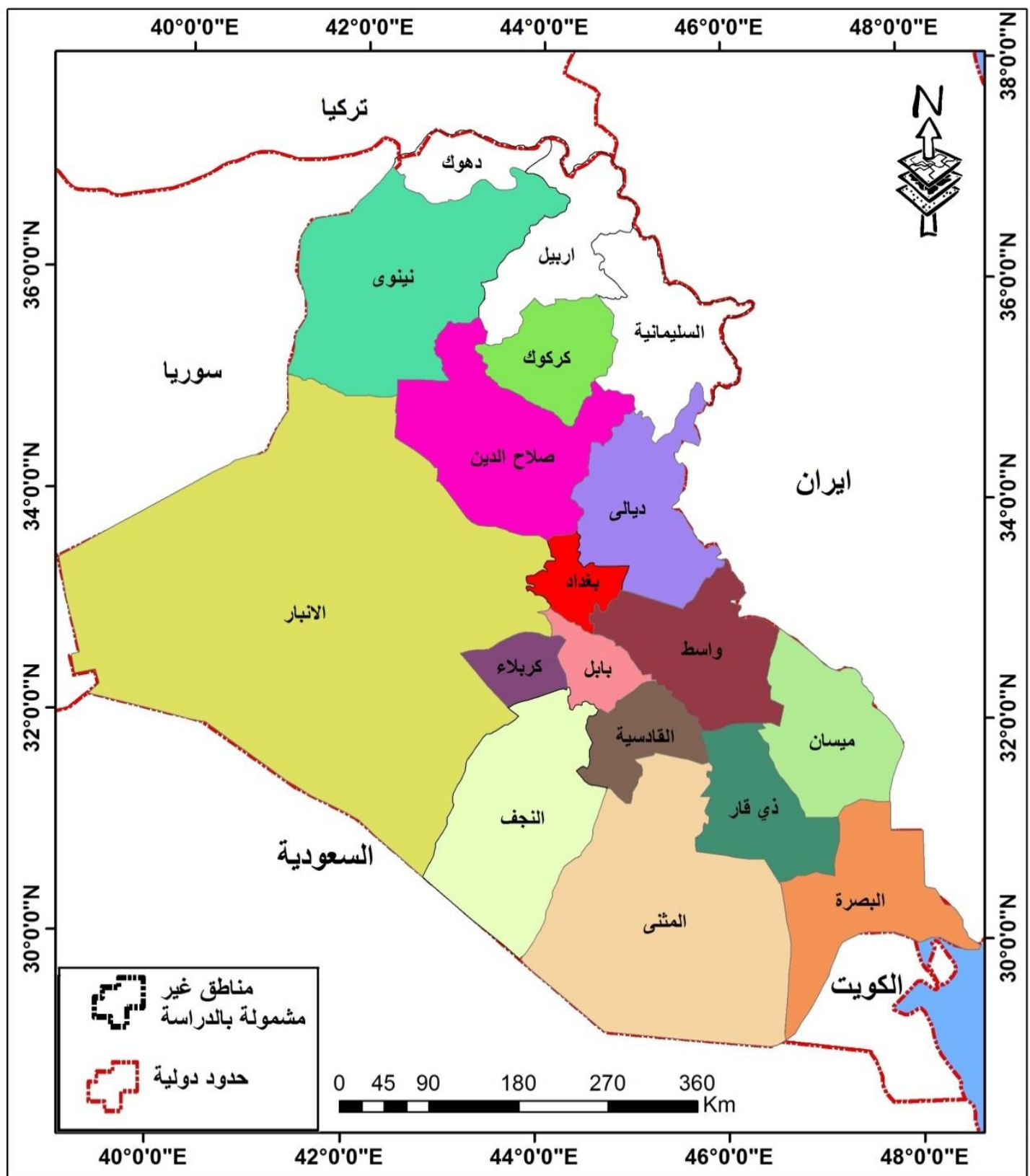

المصدر : الباحثة بالاعتماد على: جمهورية العراق، وزارة الموارد المائية، الهيئة العامة للمساحة، خريطة العراق الإدارية

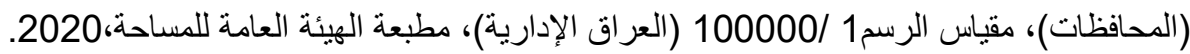

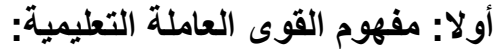

يقصد بالقوى العاملة أو السكان ذوي النشاط الاقتصادي بأنهم جميع الأفراد ذكورا و أناثا الذين يشتركون في تقديم العمل

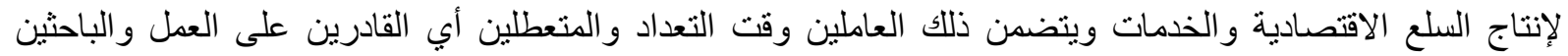

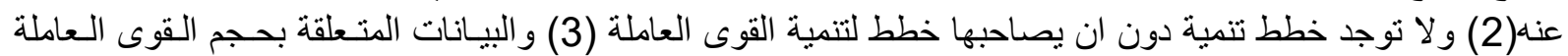


وتركيبها تساعد على تحقيق الاستثمار الأمثل للسكان (4)، الجدير بالذكر ان هناك العديد من الدراسات التي بينت الهيكل

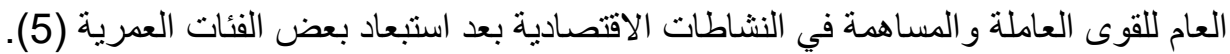

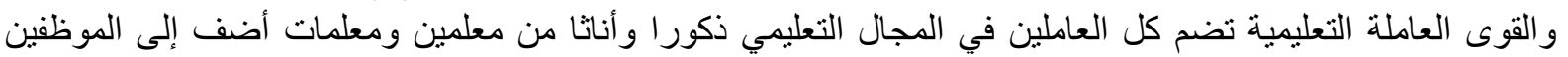

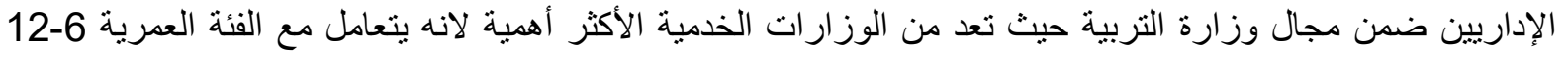

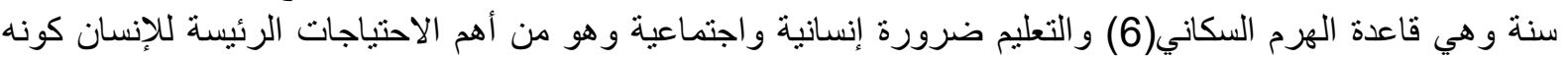

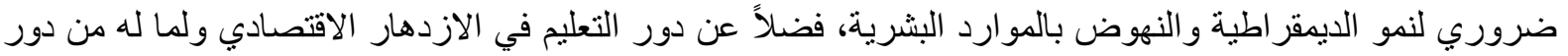

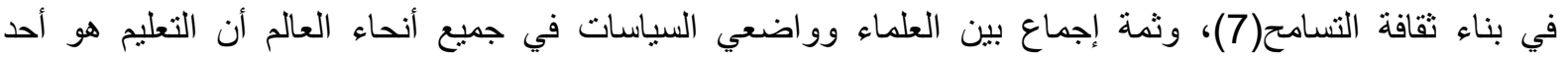

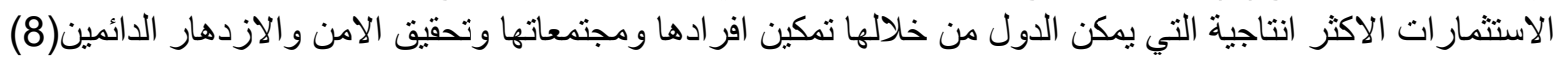

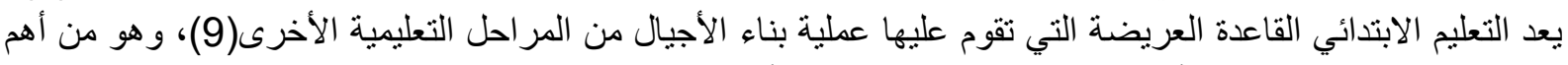

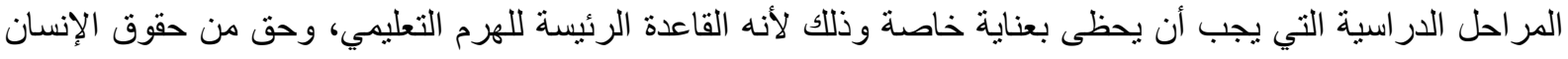

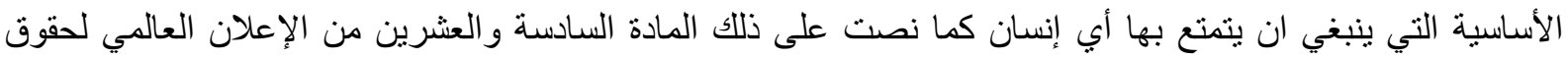

الإنسان عام 1948(10)

ثانياً: النمو السكاني للقوى العاملة التعليمية لمرحلة التعليم الابتدائي في العراق:

أن التوزيع غير المنتظم للسكان في أب بقعة يرتبط بعدد من العوامل الطبيعية والتاريخية والسياسية والحضارية التي التي التئي

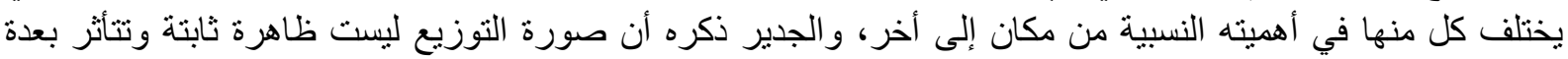

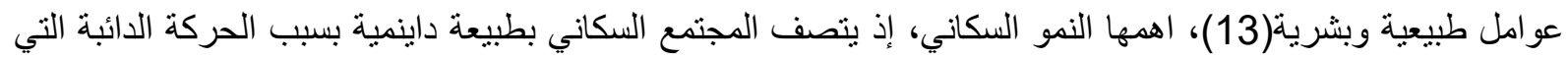

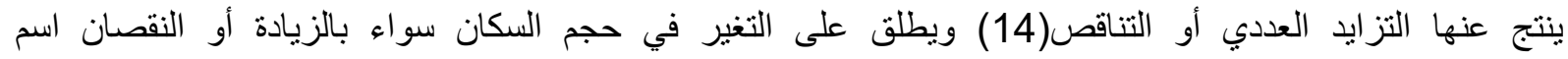

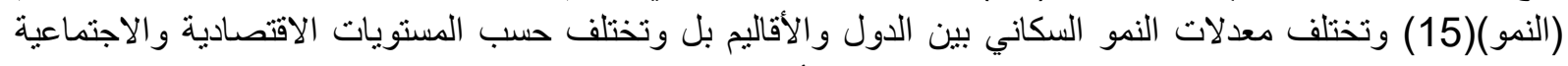

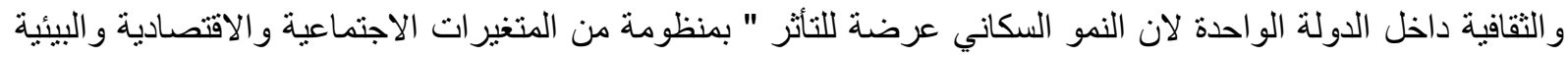

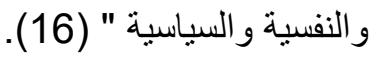

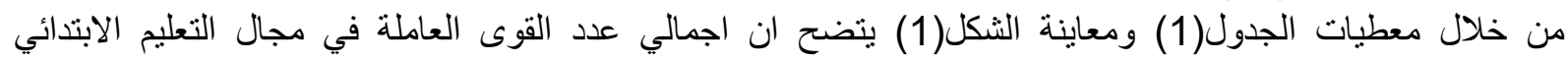

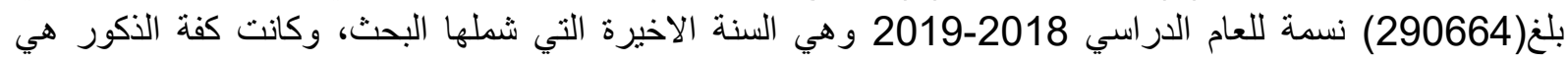

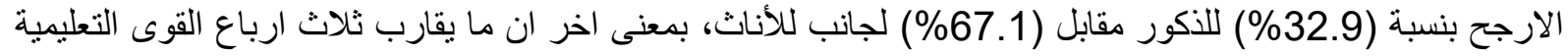

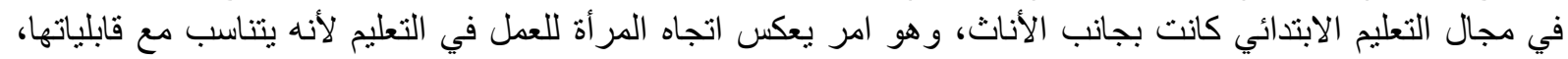

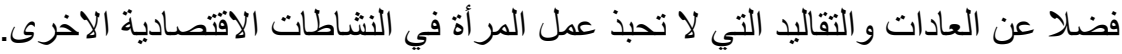

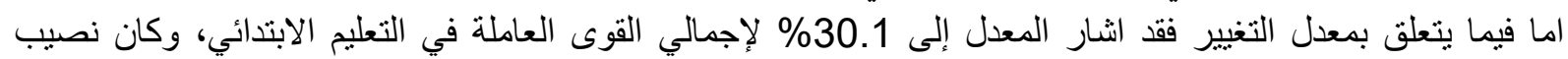

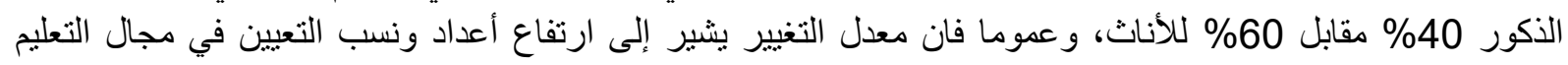

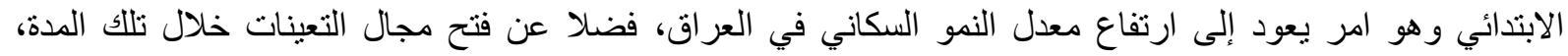

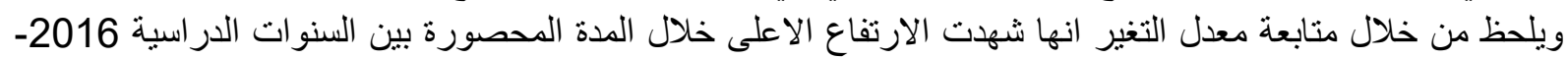

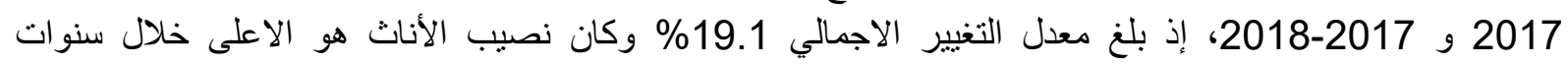

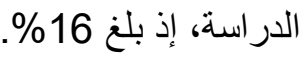

\section{ثالثاً: التوزيع الجغرافي للقوى العاملة في مجال التعليم الابتدائي:}

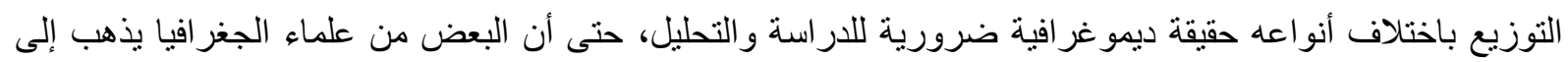

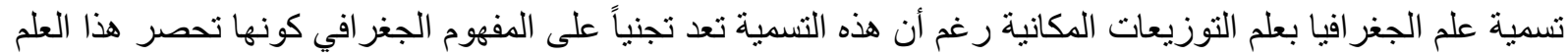
رغم توسعة في(جدول1) التطور النسبي والعددي للقوى العاملة التعليمية لمرحلة التعليم الابتدائية في العراق التئية للعام

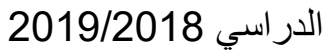




\begin{tabular}{|c|c|c|c|c|c|c|}
\hline التغيير & المجموع & التغيير & أناث & التغيير & ذكور & السنة الدر اسبة \\
\hline- & 223310 & - & 154950 & - & 68360 & $2015 / 2014$ \\
\hline 11.0 & 247919 & 10.1 & 170666 & 13.0 & 77253 & $2016 / 2015$ \\
\hline 4.8 & 259836 & 1.0 & 178004 & 5.9 & 81832 & $2017 / 2016$ \\
\hline 19.1 & 286097 & 7.4 & 191170 & 16.0 & 94927 & $2018 / 2017$ \\
\hline 1.6 & 290664 & 2.0 & 194967 & 0.8 & 95697 & $2019 / 2018$ \\
\hline
\end{tabular}

المصدر: جمهورية العراق، وزارة التخطيط، الجهاز المركزي للإحصاء، المديرية العامة للتخطيط التربوي،مديرية الاحصاء

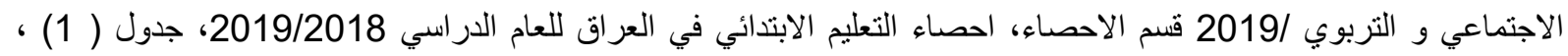
مطبعة الجهاز،2020. تم استخر اج التغير النسبي وفق القانون الآتي(14): اما التغير النسبي فكان وفق ما يأتي: $\mathbf{R}=\frac{\mathrm{p} 2-\mathrm{p} 1}{\mathrm{P} 1} \times 100$

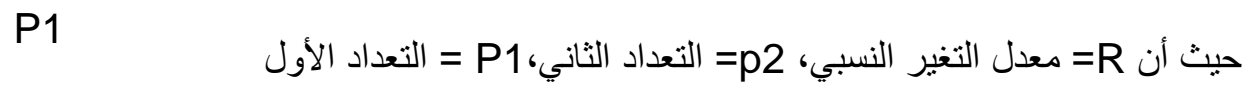
(شكل1) تطور القوى العاملة التعليمية لمرحلة التعليم الابتدائبة في العراق للعام الدراسي 2019/2018

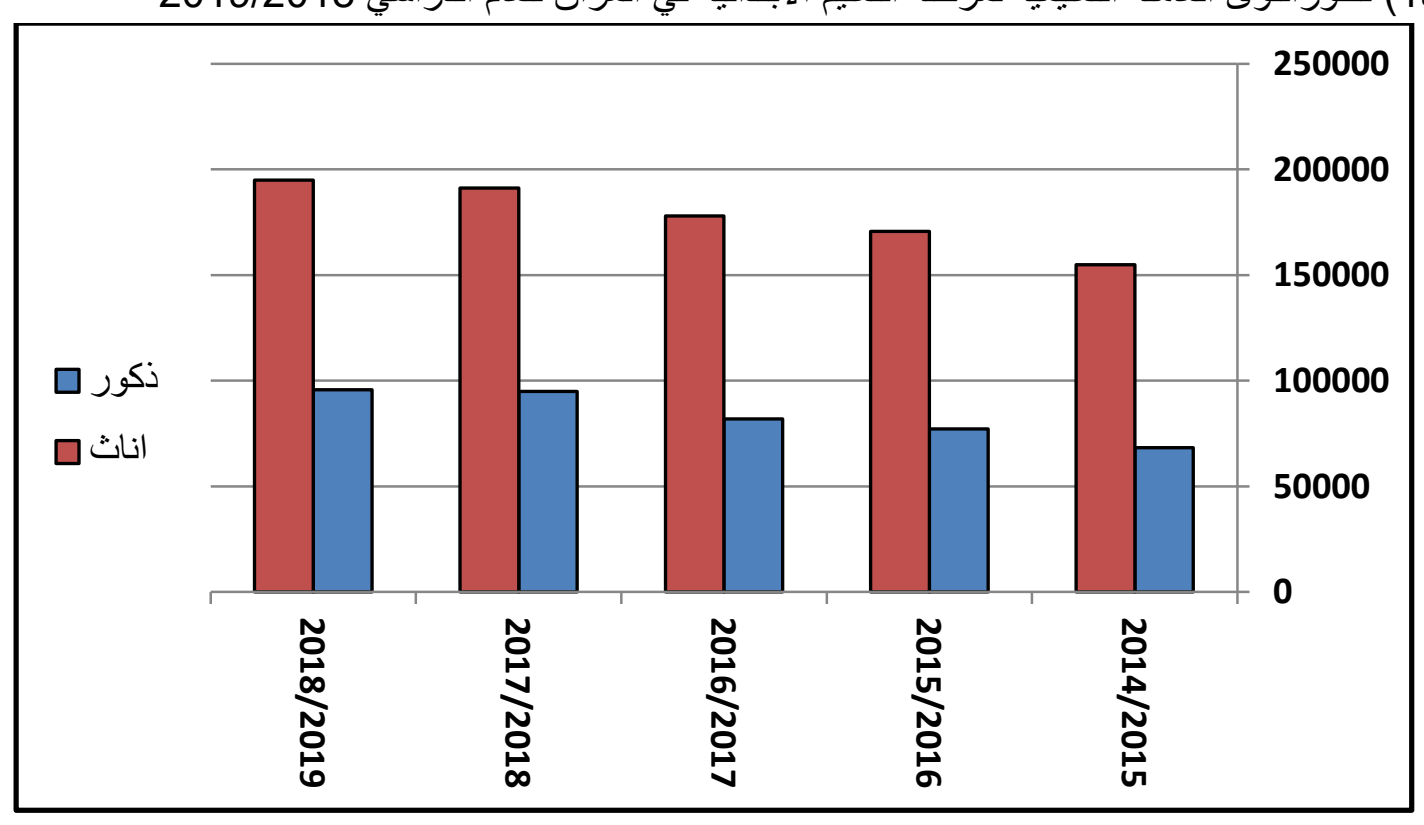

المصدر: الباحثة بالاعتماد على (جدو 1).

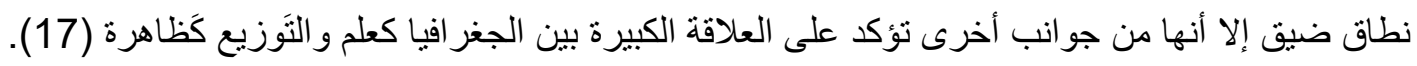

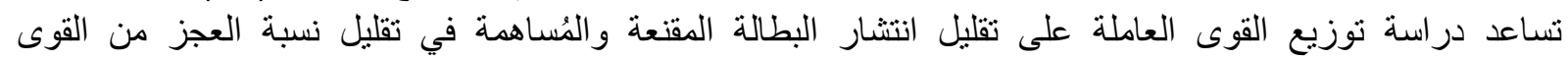

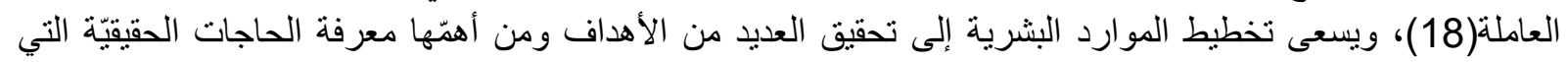

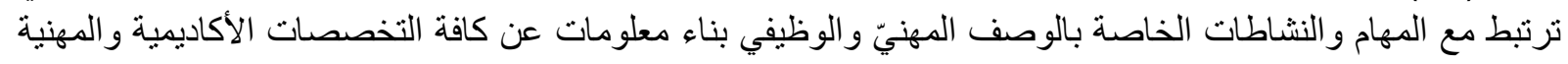




\section{GEOGRAPHICAL ANALYSIS OF THE EDUCATIONAL WORK FORCE FOR}

PRIMARY EDUCATION IN IRAQ

الخاصة وتوفير المعلومات والبيانات التي تدعم صناعة القرارات المتعلقة بالموارد البشرية واستخدام البرامج المتخصصة بتدريب القوى العاملة(19). ييلغ اجمالي القوى العاملة في مجال التعليم الابتدائي

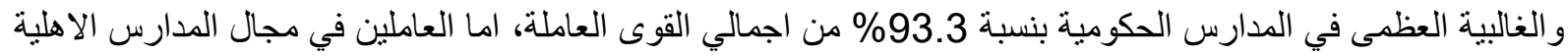

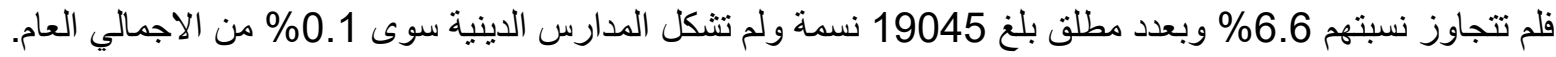

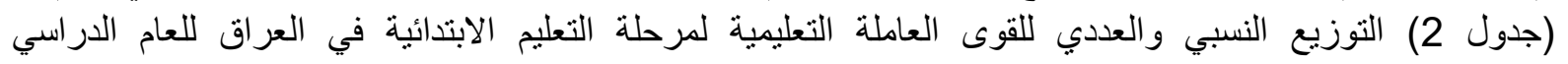

\begin{tabular}{|c|r|l|r|r|r|}
\hline & & & \\
2019/2018 \\
\hline
\end{tabular}

الدصدر: الباحثة بالاعتماد على: جمهورية العراق، وزارة التخطيط، الجهاز المركزي للإحصاء، الدديرية العامة للتخطيط

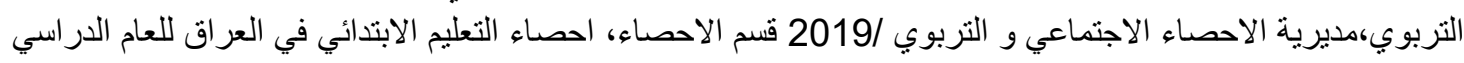
2019/2018، جدول ( 3) ، جدول (4)، مطبعة الجهاز ،2020.

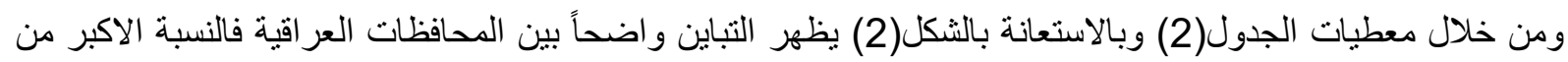

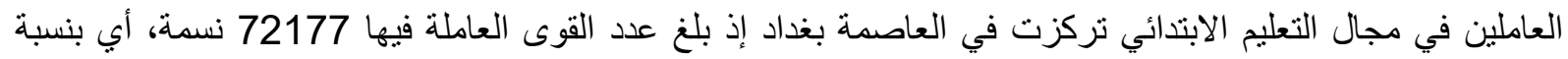

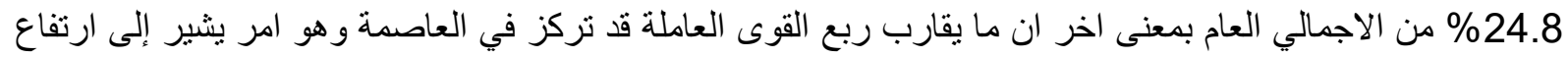

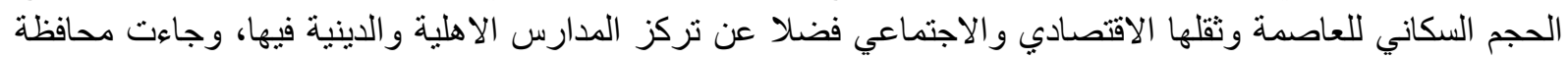

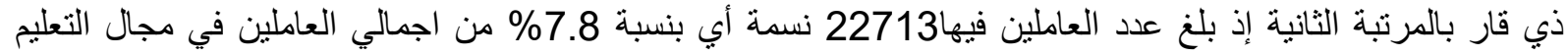
الابتدائي تلتها محافظة البصرة بعدد مطلق قدره 22014 نسمة أي بنسبة 7.6\% من اجمالي العاملين في مجال التعليم 


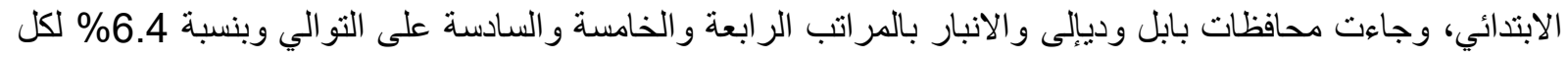

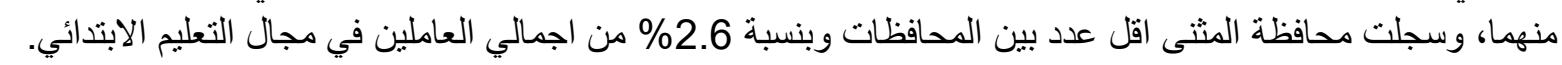

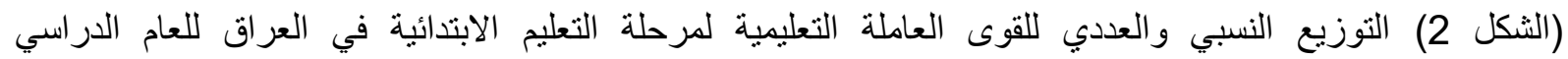
$2019 / 2018$

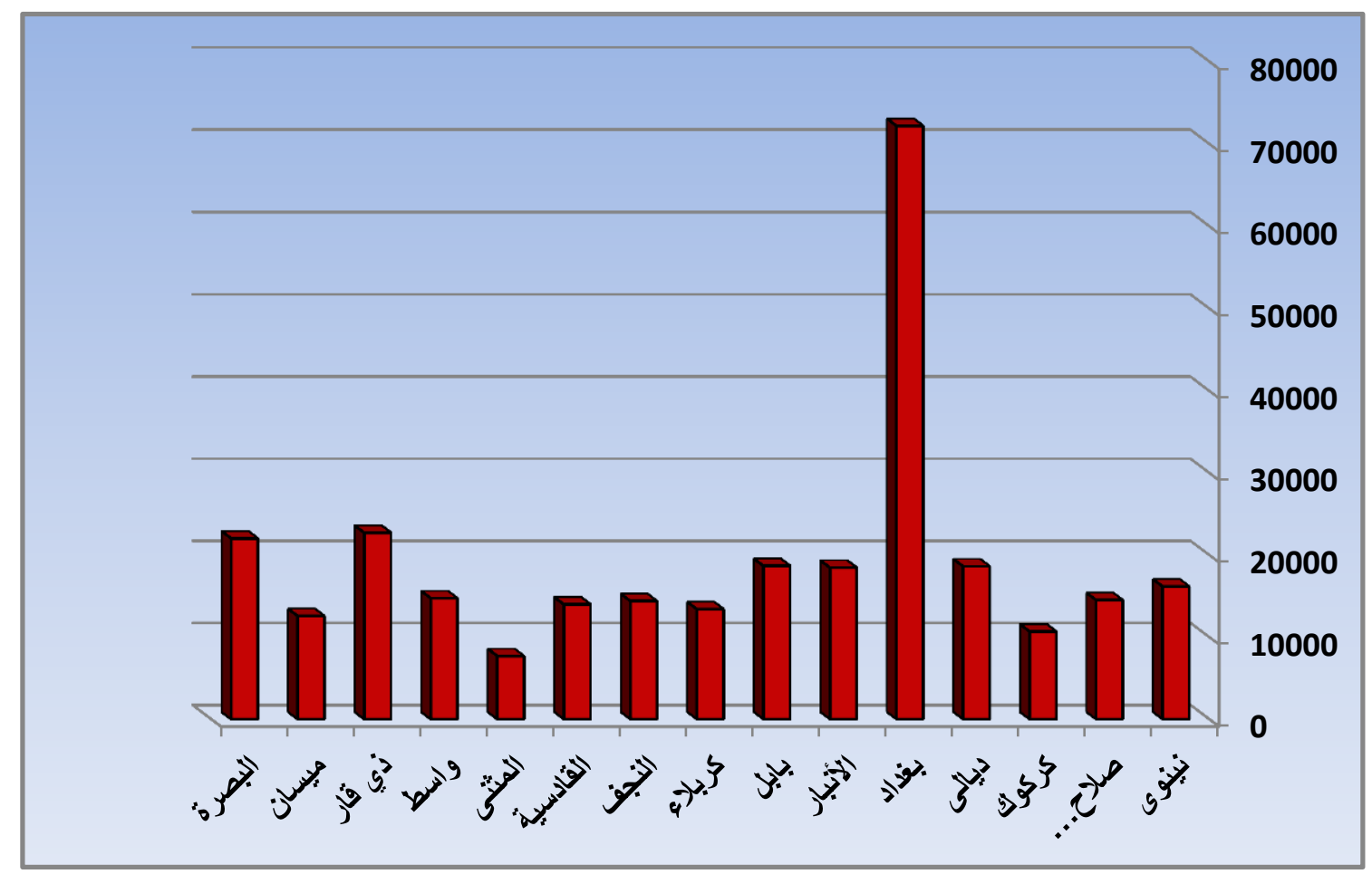

المصدر: الباحثة بالاعتماد على الجدول(2)

ومن خلال المعطيات السابقة يتضح ان حجم القوى العاملة في مجال التعليم الابتدائي لا يتناسب مع الحجم السكاني

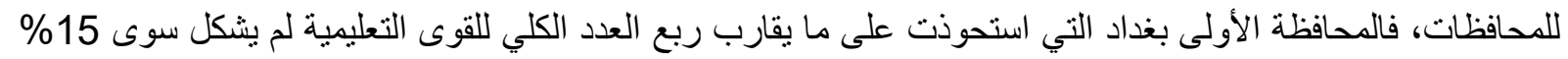

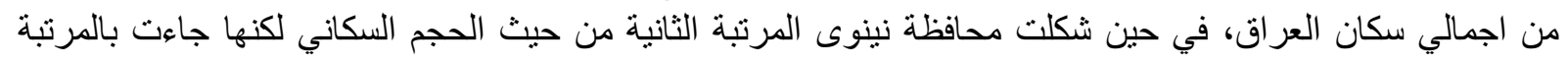

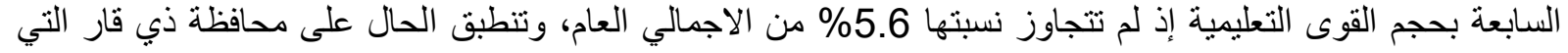

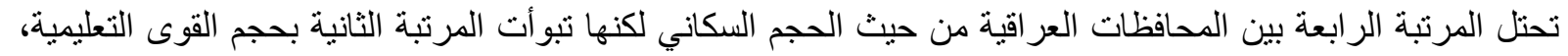

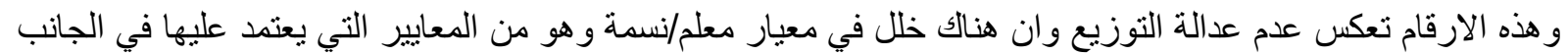

$$
\text { التربوي و التخطبطي. }
$$

\section{رابعاً: توزيع القوى العاملة التعليمية لمرحلة التعليم الابتدائي وفق النوع}

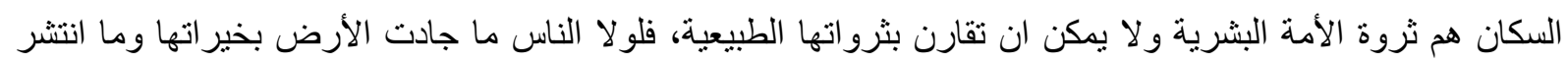

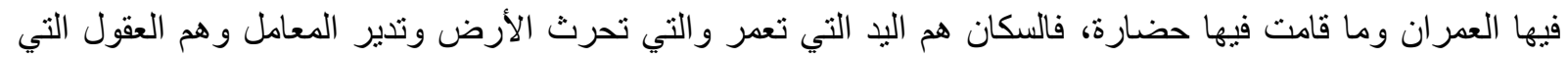

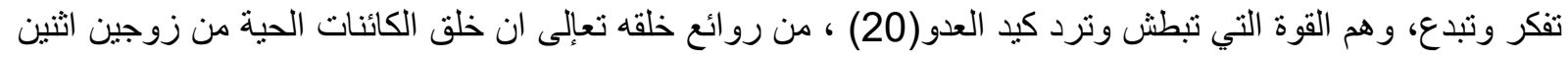

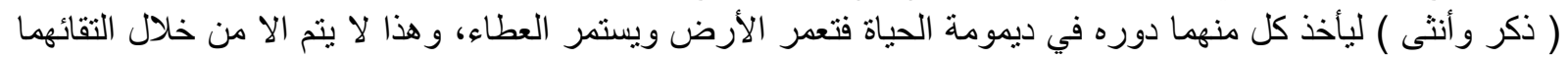

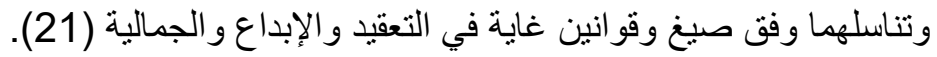

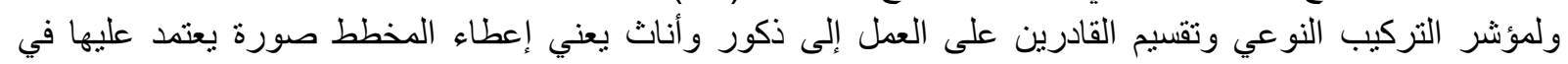

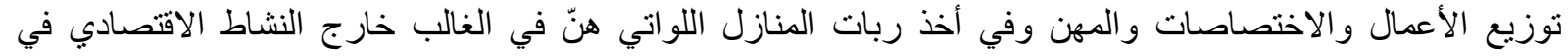

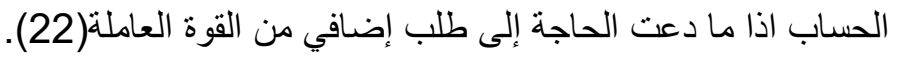

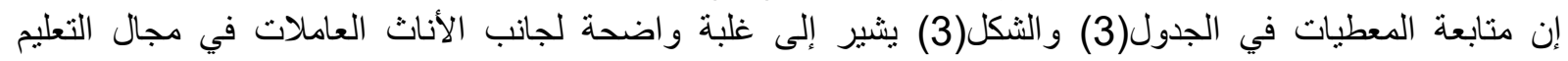
الابتدائي، إذ بلغت أعدادهن في العنات 194967 نسمة أي بنسبة 67.1\% من الاجمالي العام للقوى العاملة في مجال التعليم 
الابتدائي، في حين بلغ عدد الذكور 95697 نسمة أي بنسبة 32.9\% من اجمالي القوى العاملة التعليمية، وهذا التفاوت

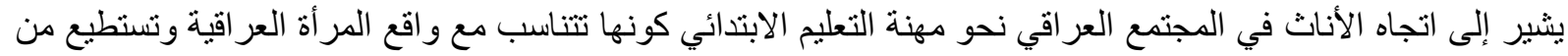

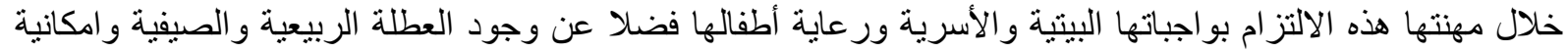

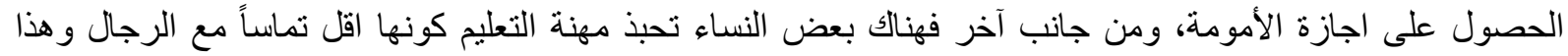
يتطابق مع ما موجود من عادات وتقاليد المجتمع العر اقي. (جدول 3) القوى العاملة التعليمية لمرحلة التعليم الابتدائي وفق النوع للعام الدراسي 2019/2018

\begin{tabular}{|c|c|c|c|c|c|}
\hline المجموع & \% & الأناث & \% & الذكور & المحافظة \\
\hline 16148 & 55.8 & 9015 & 44.2 & 7133 & نينوى \\
\hline 14499 & 61.0 & 8854 & 39.0 & 5645 & صلاح الدين \\
\hline 10677 & 64.7 & 6908 & 35.3 & 3769 & كركوك \\
\hline 18614 & 64.3 & 11968 & 35.7 & 6646 & ديإلى \\
\hline 72177 & 78.8 & 56891 & 21.2 & 15286 & بغداد \\
\hline 18458 & 58.3 & 10763 & 41.7 & 7695 & الأنبار \\
\hline 18668 & 66.6 & 12430 & 33.4 & 6238 & بابل \\
\hline 13391 & 67.2 & 9006 & 32.8 & 4385 & كربلاء \\
\hline 14374 & 67.3 & 9671 & 32.7 & 4703 & النجف \\
\hline 13979 & 62.4 & 8725 & 37.6 & 5254 & القادسية \\
\hline 7677 & 63.5 & 4879 & 36.5 & 2798 & المثنى \\
\hline 14720 & 60.4 & 8894 & 39.6 & 5826 & واسط \\
\hline 22713 & 57.5 & 13050 & 42.5 & 9663 & ذي قار \\
\hline 12555 & 59.1 & 7417 & 40.9 & 5138 & ميسان \\
\hline 22014 & 74.9 & 16496 & 25.1 & 5518 & البصرة \\
\hline 290664 & 67.1 & 194967 & 32.9 & 95697 & المجموع \\
\hline
\end{tabular}

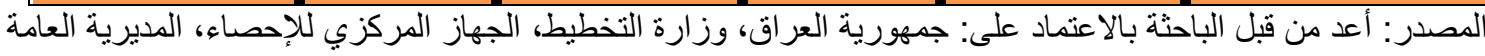

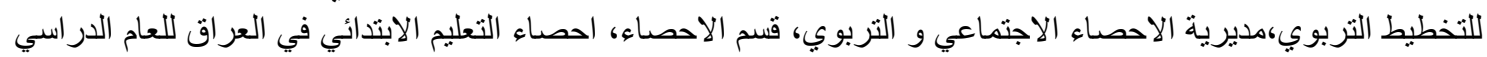
2019/2018، جدول ( 10) ، مطبعة الجهاز، 2020. 
الثكل (3) القوى العاملة التعليمية لمرحلة التعليم الابتدائي وفق النوع للعام الدراسي 2019/2018

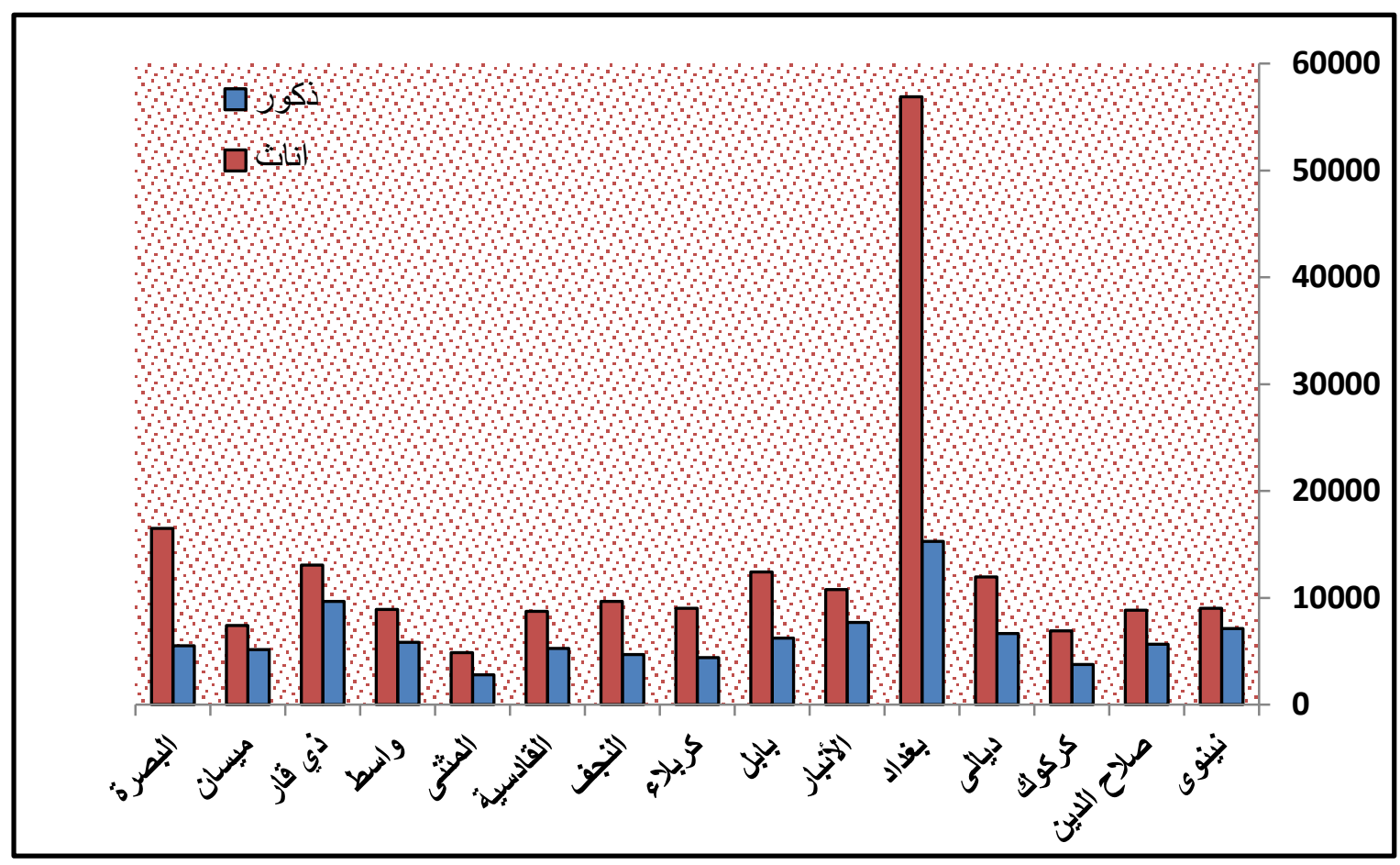

المصدر : الباحثة بالاعتماد على الجدول(3)

ويبدو التفاوت واضحا بين أعداد الذكور والأناث تبعا للمحافظات العر اقية، ويبلغ هذا التفاوت أثنده في العاصمة بغداد إذ إذاب

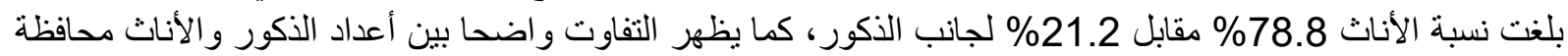

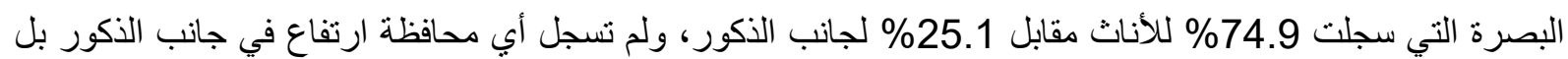
انعدم وجود التساوي بين النوعين وربما تكون محافظة نينوى هي الاقرب إلى التعادل في كفتي الموازنة رغم وجاني

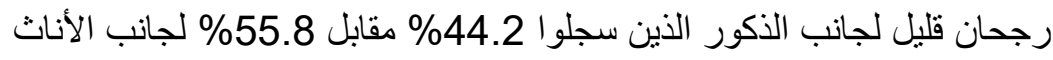

خامسا: القوى العاملة التعليمية لمرحلة التعليم الابتدائي وفق البيئة ريف/حضر

يتم التمييز بين الريف والحضر وفقاً لمعايير لا تقتصر على الحجم السكاني، بل تتنتمل على متغيرات اقتصادية واجتماعية

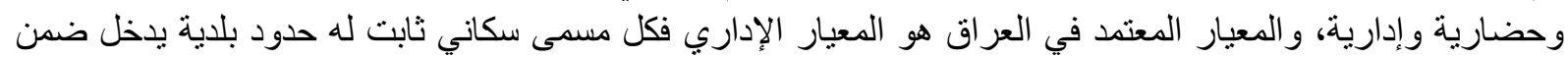

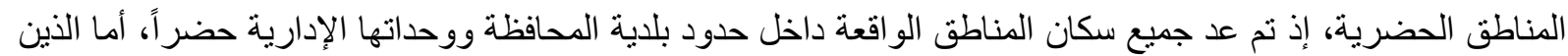

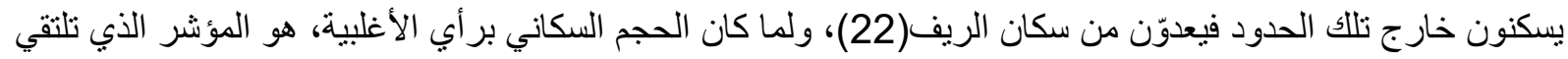

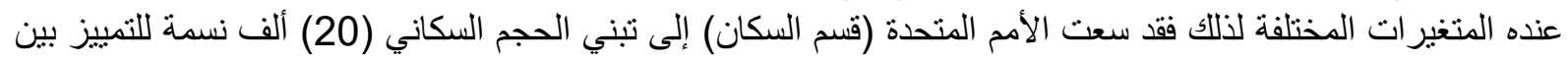
المستوطنات الحضرية وغير الحضرية(24).

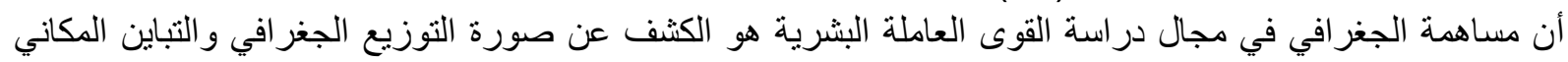

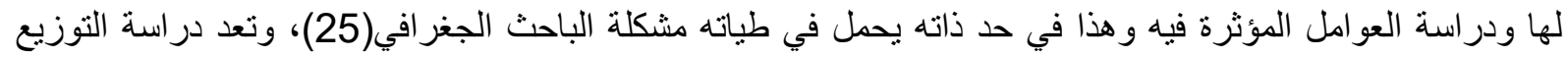

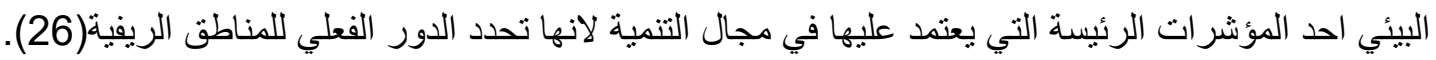

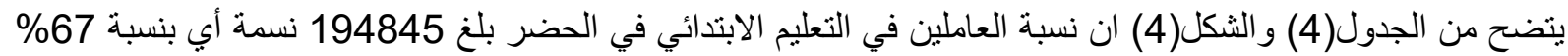
من الاجمالي العام ويكاد يتفق هذا الرقم مع نسبة الحضر في العراق و البالغة 65\% بحسب التئ الجهاز المركزي للاحصاء،

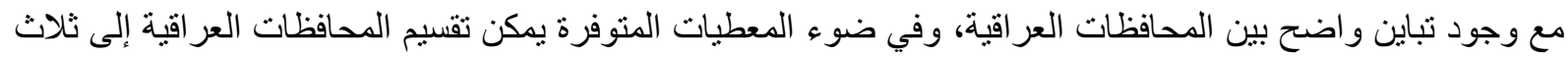

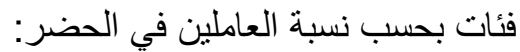

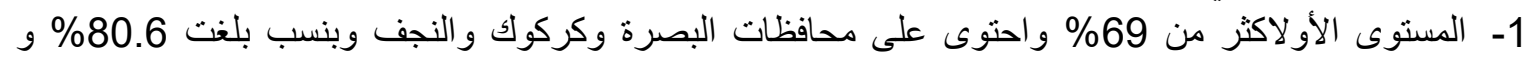

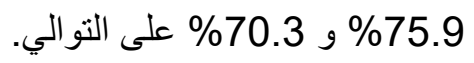




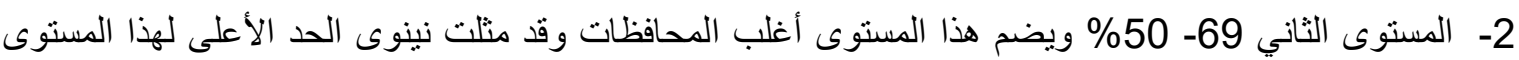
بنسبة 69\% بينما منلت الانبار الحد الأدنى بنسبة 50\% 3- المستوى الثالث اقل من 50\% و وانطوى تحت هذا المستوى اربعة محافظات هي المثنى وبابل وديإلى وصلاح الدين ومثلت الاخيرة الحد الادنى لهذه الفئة بنسبة ونة جدول( 4) القوى العاملة التعليمية لمرحلة التعليم الابتدائي وفق البيئة للعام الدراسي 2019/2018

\begin{tabular}{|c|c|c|c|c|c|}
\hline المجموع & $\begin{array}{r}\text { النسبة } \\
\text { \% }\end{array}$ & الريف & $\begin{array}{r}\text { النسبة } \\
\%\end{array}$ & الحضر & المحافظة \\
\hline 16148 & 30.5 & 4918 & 69.5 & 11230 & نينوى \\
\hline 14499 & 50.6 & 7343 & 49.4 & 7156 & صلاح الدين \\
\hline 10677 & 24.1 & 2571 & 75.9 & 8106 & كركوك \\
\hline 18614 & 54.7 & 10174 & 45.3 & 8440 & ديإلى \\
\hline 72177 & 14.1 & 10145 & 85.9 & 62032 & بغداد \\
\hline 18458 & 46.4 & 8558 & 53.6 & 9900 & الأنبار \\
\hline 18668 & 50.8 & 9476 & 49.2 & 9192 & بابل \\
\hline 13391 & 35.9 & 4812 & 64.1 & 8579 & كربلاء \\
\hline 14374 & 29.7 & 4275 & 70.3 & 10099 & النجف \\
\hline 13979 & 37.4 & 5230 & 62.6 & 8749 & القادسية \\
\hline 7677 & 65.5 & 4258 & 44.5 & 3419 & المثنى \\
\hline 14720 & 44.9 & 6611 & 55.1 & 8109 & و اسط \\
\hline 22713 & 40.4 & 9180 & 59.6 & 13533 & ذي قار \\
\hline 12555 & 31.9 & 3999 & 68.1 & 8556 & ميسان \\
\hline 22014 & 19.4 & 4269 & 80.6 & 17745 & البصرة \\
\hline 290664 & $\% 33$ & 95819 & $\% 67$ & 194845 & المجموع \\
\hline
\end{tabular}

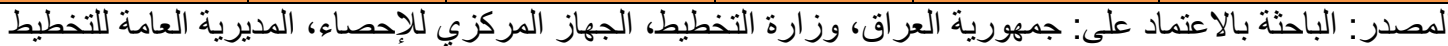

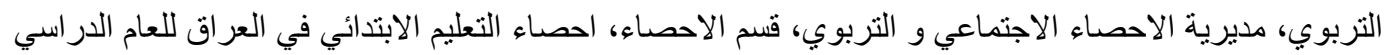
2019/2018، جدول ( 8) و (9) ، مطبعة الجهاز،2020. 
(الثكل 4) القوى العاملة التعليمية لمرحلة التعليم الابتدائي وفق البيئة للعام الدراسي 2019/2018

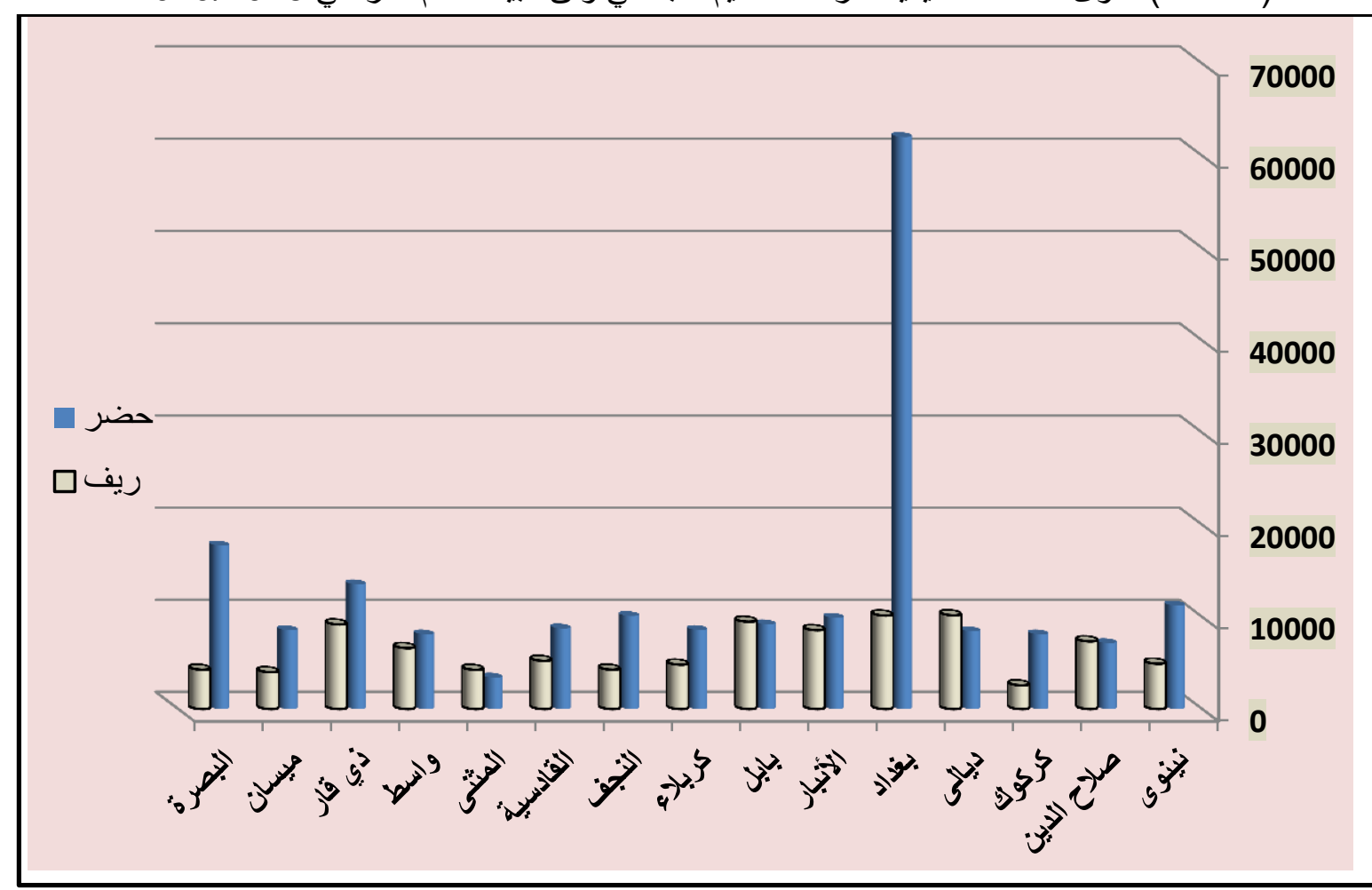

الدصدر: الباحثة بالاعتماد على الجدول(4) و عموما فان العرض السابق يؤكد ان هناك ترابط بين الدحافظات ذات الغلبة الحضرية

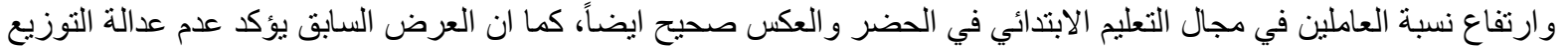
وعدم توزيع ثمار التنمية بشكل متساوي.

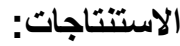

1- بلغ عدد القوى التعليمية في التعليم الابتدائي للعام الدراسي 2018-2019 (2015 (200664) معلماً ومعلمة وبواقع

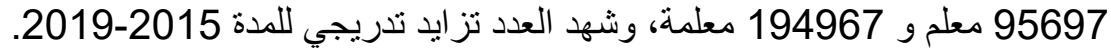

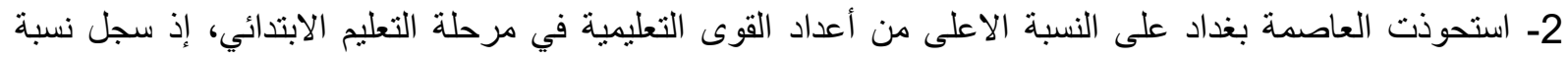

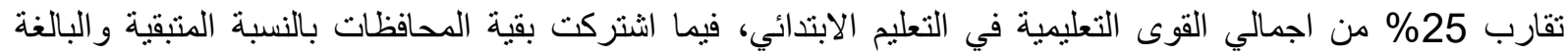
$\% 75$

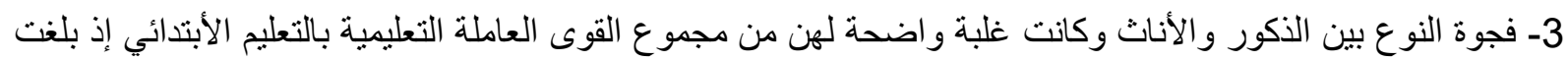
نسبة الأناث 78.8\% مقابل 21.2\% لجانب الذكور، كما بظهر التفاوت واضحا بين أعداد الذكور و الأناث في محافظة البصرة التي سجلت 74.9\% للانياث مقابل 25.1 \% 25.

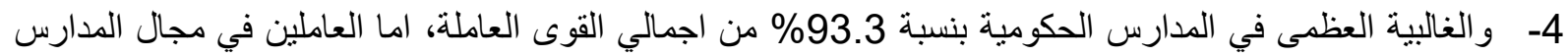
الاهلية فلم تتجاوز نسبتهم 6.6\% ولم تشكل الددارس الدينية سوى 0.1\% من الاجمالية العالي العام للقوى العاملة.

التوصيات:

1-يوصي الباحث بضرورة ان يكون هناك نوزيع عادل للقوى التعليمية على مستوى المحافظات وان يكون ذللك متلائماً

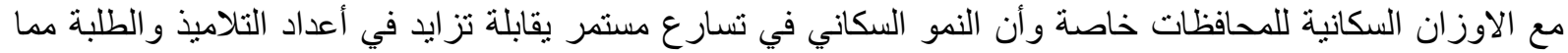
ييتطلب نوظيف أعداد جديدة من القوى العاملة وبشكل مستمر ويجب أن تكون الدرجة الوظيفية حسب الحاجة والنوع 
2- التركيز على تعيين التخصصات التي تعاني من عجز من القوى التعليمية على مستوى المحافظات ودمج الخريجين الجدد لكليات التربية بالمؤسسات التربوية من خلال العقود السنوية للحد من ظاهرة البطالة بين الخريجين أضف إلى الى قيام

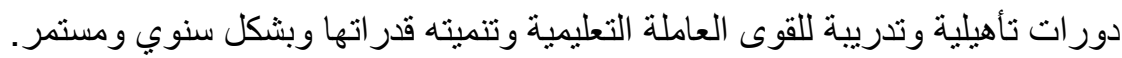

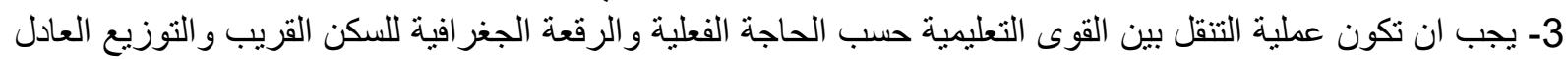
للكو ادر التعليمية بين الريف والحضر وبين مركز المدينة والأطر اف وسد النقص للقوى العاملة التعليمية لكي نتمكن من التهن تحقيق كفاءة التوزيع مستقبلا ومعالجة الصعوبات التي تواجها من أجل تطبيق واجباتها بأريحية وبدرجة التهائ عالية من الرضا.

المصادر

ابراهيم، حسين علوان القوى العاملة في صلاح الدين دراسة في التباين المكاني، مجلة كلية التربية، جامعة تكريت،

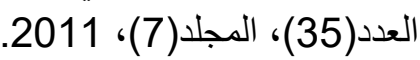

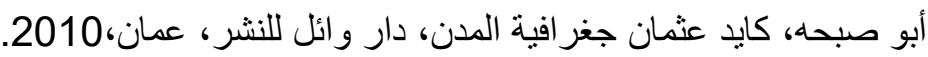

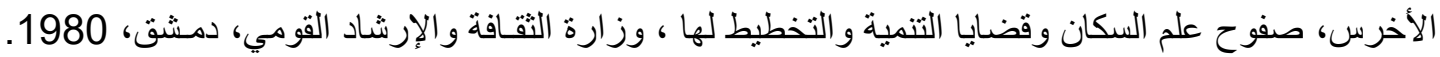

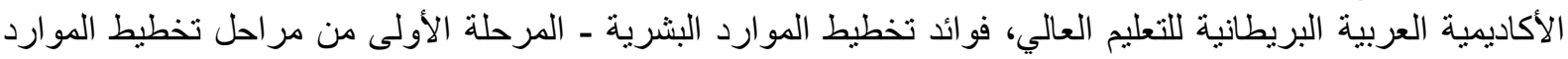
البشرية.

البـدري، منذر عبد المجيد، القوى العامـلة في العراق 1975- 1977. 1980. دراسة في الجغر افية البشرية، اطروحة دكتور اه

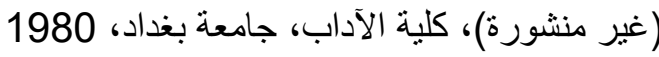

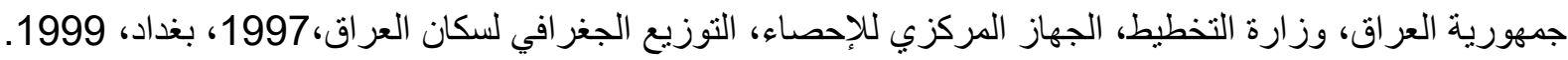

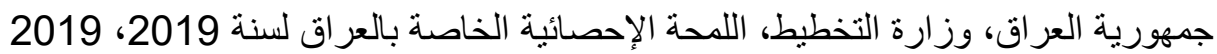

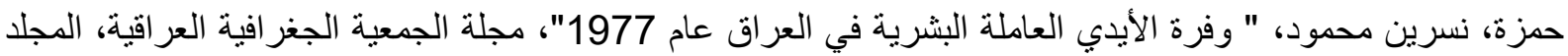

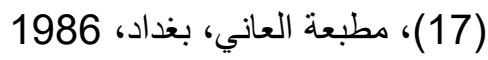

الخفاف، عبد علي و عبد مخور الريحاني، جغر افية السكان، جامعة البصرة، البرة، 1986.

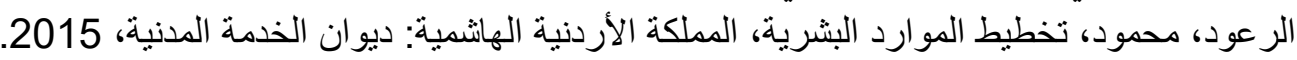

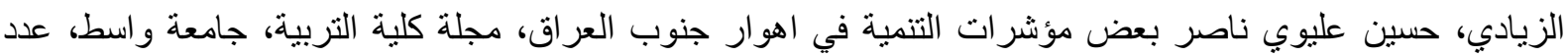

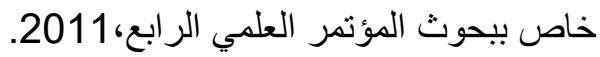

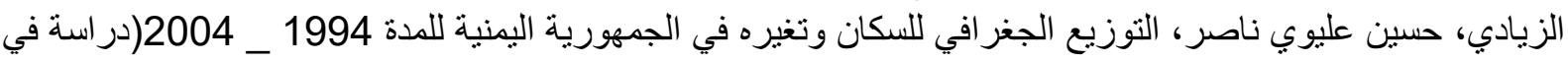

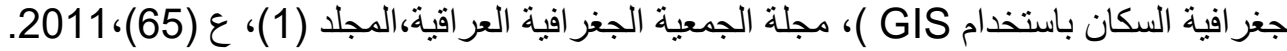

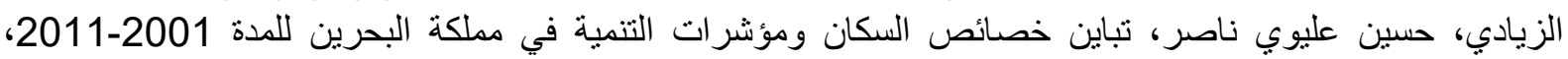

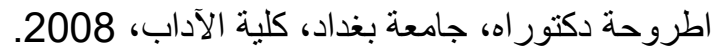

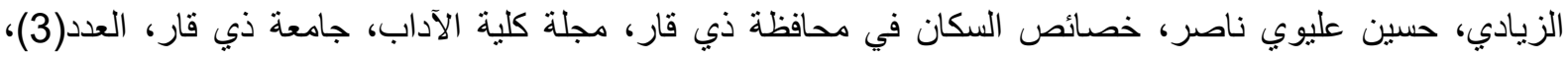

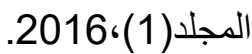

السعدي، عباس فاضل نمو السكان في لييا إلى اين يتجه ، وما هي عوامل مكوناته، مجلة البحوث والدراسـات

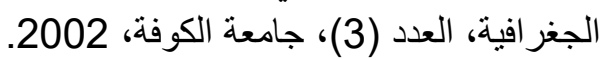

السعدي، عباس فاضل، دور نمو السكان وتوزيعهم في قوة الدولة، دراسة، الطية تطبيقية على الوطن العربي، مجلة كلية الآداب،

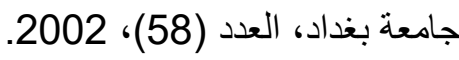

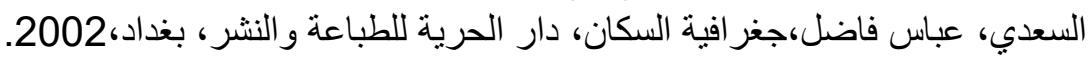

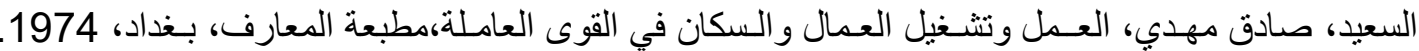

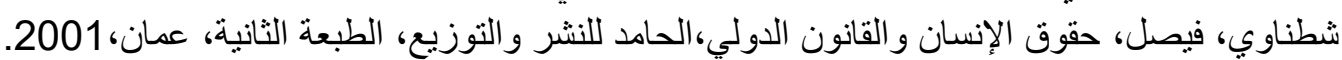

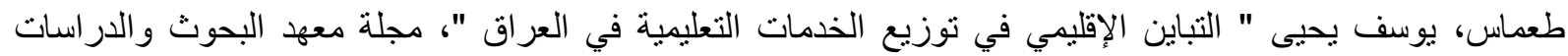

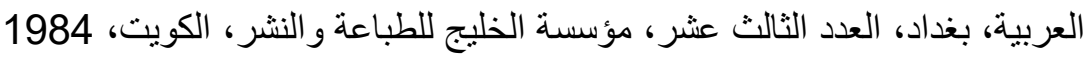

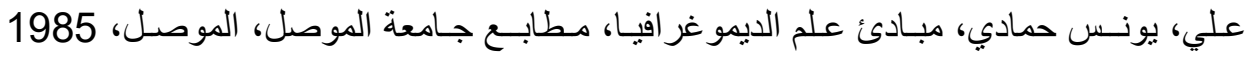
فتحي محمد ابو عيانة، مشكلات السكان في الوطن العربي، دار المعرفة الجامعية، الاسكندرية، 1987. 
الفر اج، عبد المجيد، الأسس الإحصائية للار اسات السكانية، دار النهضة العربية، القاهرة، 1975. القيسي، اسيل أبر اهيم طالب التركيب التعليمي لسكان محافظة بغداد للمدة 1997- 2013، الإنة الطروحة دكتور اه (غ.

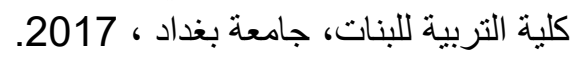
ليو جيان وآخرون، التعليم من اجل المستقبل التجربة العالمية لتطوير مهارات وكفاءات اللقات القرن الحادي و العشرين, مؤتمر

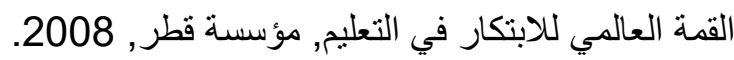

مخلف، لمياء احمد، التركيب التعليمي لسكان العراق , اطروحة دكتور اهن , كلية التربية،الجامعة المستتصرية ,2013.

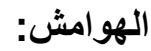

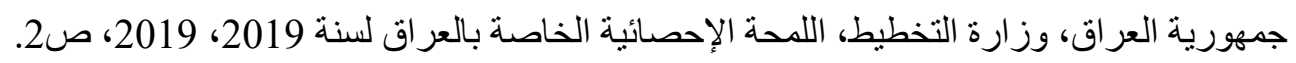

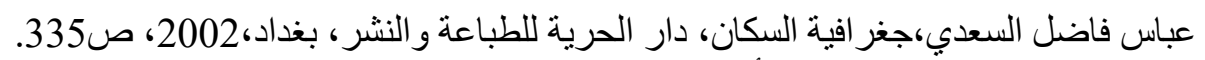

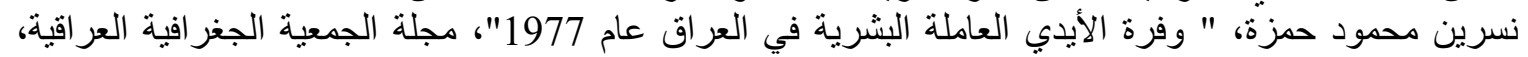

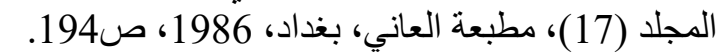

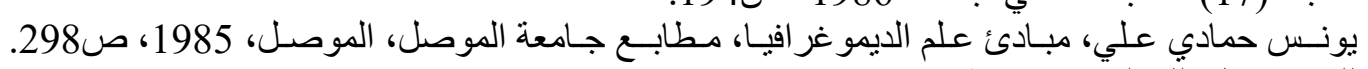

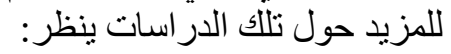

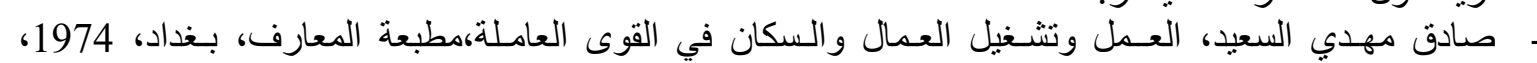

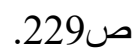
منذر عبد المجيد البـدري، القوى العامـلة في العراق 1975- 1977، 1977. دراسة في الجغرافية البشرية، اطروحة

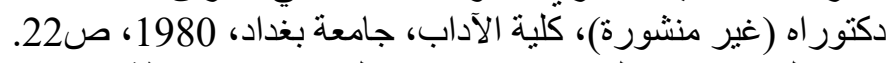

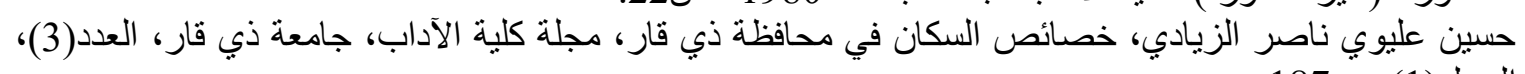
لمياء احمد مخلف , التركيب التعليمي لسكان العراق , اطروحة دكتوراه , كلية التربية ,الجامعة المستتصرية 2013, ليو جيان وآخرون, التعليم من اجل المستقبل التجربة العالمية لتطوير مهارات وكفاءات القرن الحادي والعشرين,

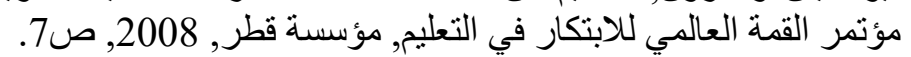

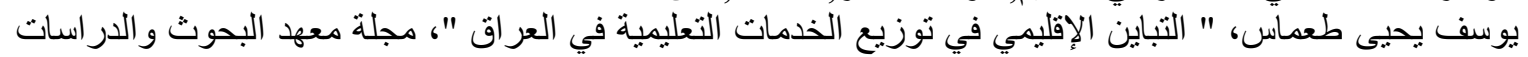

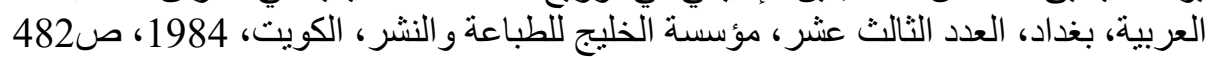

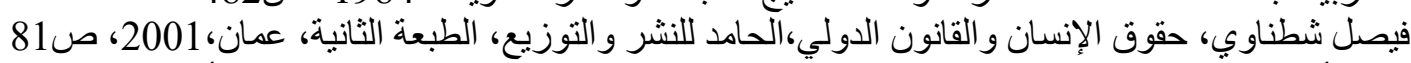

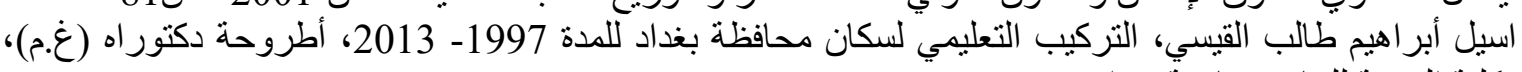

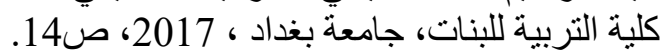

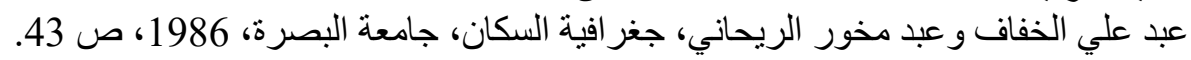

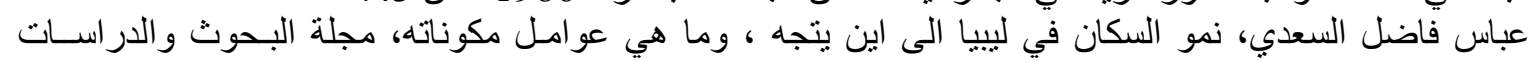

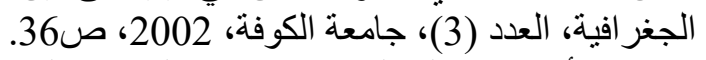

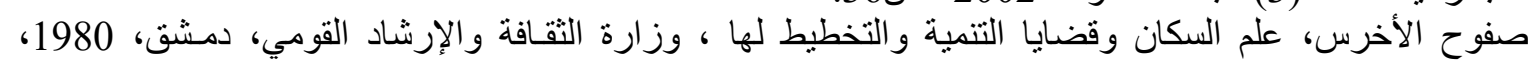
(16)

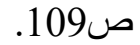

(14) عبد الدجيد الفر اج، الأسس الإحصائية للار اسات السكانية، دار النهضة العربية، القاهرة، 1975، ص 145-147.

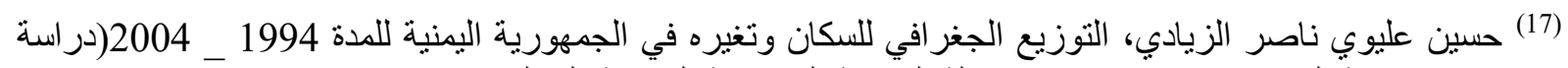

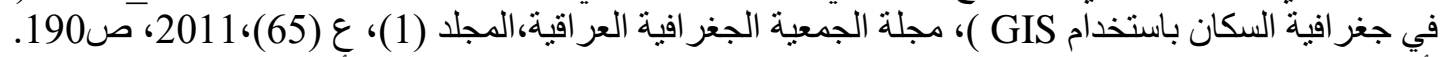
(18) الأكاديمية العربية البريطانية للتعليم العالي، فو ائد تخطيط الموارد البشرية ـ المرحلة الأولى من مر احل تخطيط الموارد

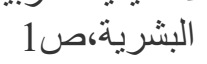

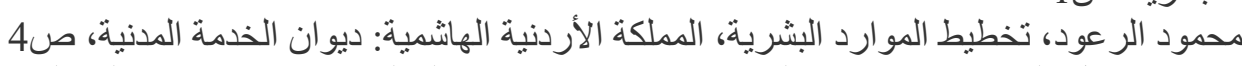

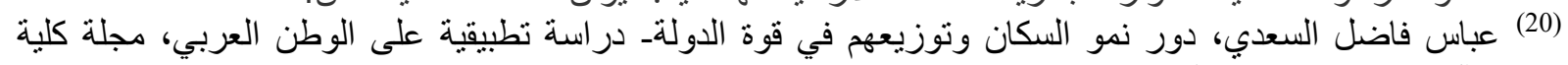

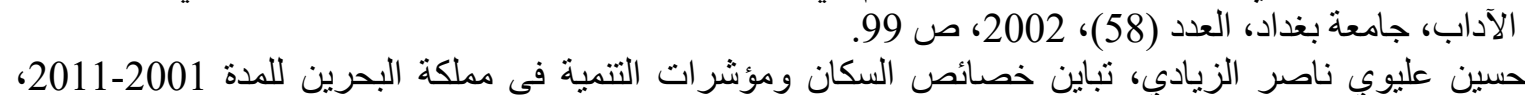

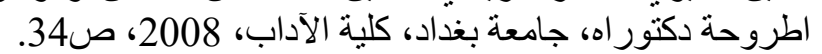
فتحي محمد ابو عيانة، مشكلات السكان في الوطن العربي، دار المعرفة الجامعية، الاسكندرية، 1987، ص87. 
(23) جمهورية العراق، وزارة التخطيط، الجهاز المركزي للإحصاء، التوزيع الجغرافي لسكان العراق،1997، بغداد،

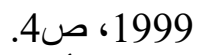

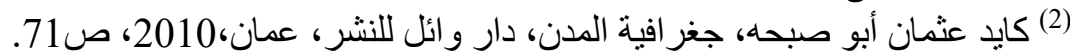

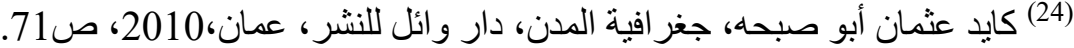

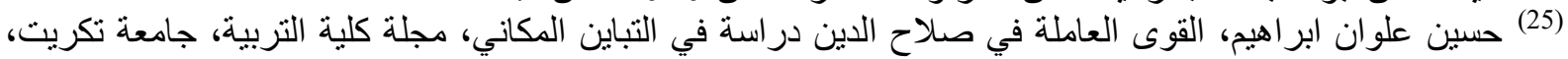

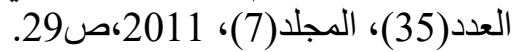
(26) حسين عليوي ناصر الزيادي، بعض مؤشرات التنمية في اهو ار جنوب العراق، مجلة كلية التربية، جامعة واسط، عدد

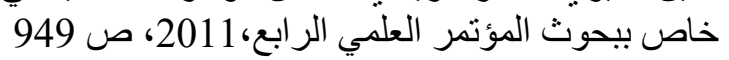

